\title{
Mit Kindern über Brustkrebs
}

\section{reden}

Manchmal finde ich, Mama hat sich verändert.

Mamas Haare fehlen, und ihre Brust ist auch weg.

«Mama», sage ich, «du siehst jetzt schon etwas anders aus, so ohne Haare und ohne Brust."

Ja", sagt Mama, «das stimmt. Ich sehe jetzt etwas anders aus. Aber ich habe dich noch immer genauso lieb wie vorher, und nichts in der Welt wird daran etwas ändern. und nichts in deroladeneis über alles. Wollen wir uns eins kaufen gehen?» «Ja», sage ich, «gute Idee, Mama.»

Was geht in Kindern vor, wenn ihre Eltern schwer erkranken? Wie soll man ihnen erklären, weshalb der Mutter plötzlich die Kraft fehlt, sich so wie früher um sie zu kümmern? Wie ihnen verständlich machen, dass sie keinen Lärm machen dürfen, weil Mama mitten am Tag schlafen muss? Wo bleiben die Bedürfnisse des Kindes, wenn sich alles nur noch um die kranke Mutter dreht? Ein liebevoll illustriertes Bilderbuch erzählt über den Alltag und die Sorgen der kleinen Lulu, die lernen muss, mit der Krankheit ihrer Mutter zu leben und diese zu verstehen.

Das Buch richtet sich an Kinder zwischen zwei und acht Jahren und erklärt auf altersgerechte Weise, was Brustkrebs ist und wie sich die Krankheit und ihre Behandlung auswirken kann. Und es unterstützt Eltern darin, mit ihren Kindern über das Unfassbare zu reden.

Lulu backt am liebsten zusammen mit Mama Kuchen, die besten weit und breit. Und sie spielt gerne Piratin, und Piratinnen sind bekanntlich nicht besonders leise. Doch Mama ist manchmal einfach zu müde, um mit Lulu zu backen oder zu spielen. Sie muss sich oft ausruhen und verträgt dann keinen Lärm. Mama hat Brustkrebs. «Weisst du, Lulu», erklärt sie, «mir gefällt die Chemotherapie nicht. Manchmal wird mir richtig schlecht davon, und sie macht mich kribbelig und manchmal schlecht gelaunt. Aber sie ist nötig, damit wir den Krebs vertreiben können.» Das ist nicht immer einfach für Lulu, es macht sie traurig und manchmal richtig wütend. Dann muss sie herumtoben und brüllt sogar ihren Stoffhasen Hoppel an, dem sie sonst alle Geheimnisse anvertraut.

Und doch kann das kleine Mädchen der Krankheit ihrer Mutter auch positive Seiten abgewinnen: So hat sie manchmal ihren Papa ganz für sich allein, oder sie schlägt bei der Oma die Trommeln, so laut, dass die Katze fauchend die Flucht ergreift. Und ihre Mama, die so anders aussieht ohne Haare und ohne Brust, die hat sie genau so lieb wie vorher, daran besteht kein Zweifel. Und so setzen sich Mutter und Tochter zusammen ins Gras und schauen die Sterne an. «Weisst du was», sagt Mama, «manchmal bin ich müde, manchmal muss ich ins Spital, manchmal bin ich traurig und manchmal bin ich wütend. Aber immer, Lulu, immer, immer bist du mir das Allerliebste auf der Welt.»

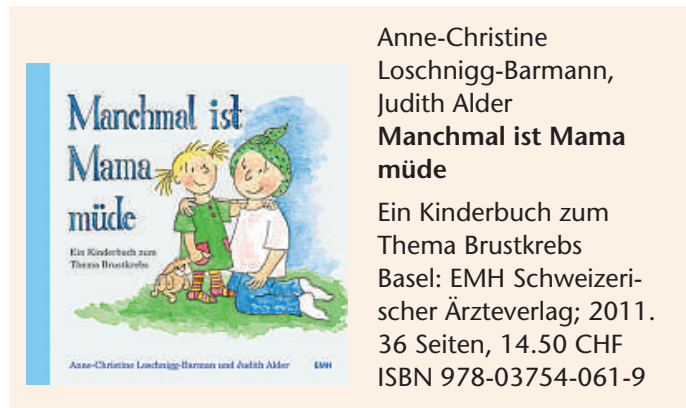

